\title{
Spatial Quality of Social Housing for Seniors: Village of the Elderly in São Paulo (Brazil)
}

\author{
Rosio Fernandez Baca Salcedo ${ }^{1}$, Renata Cardoso Magagnin ${ }^{1}$ and Talita Cristina Pereira ${ }^{2}$ \\ 1. Architecture, Arts and Communication Faculty, UNESP (Univ. Estadual Paulista), Bauru 17033-360, Brazil \\ 2. Architecture and Urbanism, UNESP (Univ. Estadual Paulista), Bauru 17033-360, Brazil
}

\begin{abstract}
This paper presents the quality assessment of the built environment in the social housing for seniors "Village of the Elderly", located in the central area of São Paulo (Brazil) and it is the case study analyzed here. This multi-method study aimed to evaluate the quality of the built environment through the following indicators: community public facilities in the neighborhood, accessibility, safety and quality of housing. The results showed that "Village of the Elderly" was designed to house residents with income of up to three minimum wages, however, for lack of specific technical knowledge on human aging, some problems related to accessibility and safety of residents were neglected. The research contributes to studies on the quality of the ambience of constructed space and the results can support public policies, programs and projects of social housing for the elderly.
\end{abstract}

Key words: Social housing, Social Rental Program, built space quality, central area.

\section{Introduction}

According to data provided by the UN (United Nations) [1], the world is going through a demographic transition caused by the aging population and the declining fertility rate.

According to the Pan American Health Organization [2], the ageing index in Brazil in the coming decades will have a higher rate than in other countries; By 2025, this rate will be five times greater than that presented in 1975. It is estimated that in 2050 the Brazilian population aged 65 and over will represent $20 \%$ of the total population (approximately 50 millions). This value is greater than currently found in any European country. "So Brazil will be faced with the difficult situation of having to assist an increasingly aging society in a much shorter period than that experienced by developed countries" [2]. The analysis of the population data of São Paulo City showed that in 2000 people aged 60 and over accounted for a total of $9.32 \%$ and in 2010 this age

Corresponding author: Rosio Fernandez Baca Salcedo, Ph.D., professor, research fields: social housing, architectural and urban heritage, dialogic architecture and historic center. group represented $11.7 \%$ [3]. Faced with the sharp pace of population aging, the demand for housing and community public facilities also increased, exacerbating the housing shortage for the elderly.

According to Monteiro [4], there is a global trend in the reduction of seniors living with their own children. Research shows that a significant part of this population is living alone, a phenomenon known as single person household. According to Census 2000, $19.4 \%$ of São Paulo's elderly lived alone [3]. Moreira [5] explains that the reasons for this growing phenomenon in the country are:

- the weakening of the family base as support in old age;

- the neglected contribution to social welfare programs;

- the debilitated institutional forms to support the elderly and which place policies, programs and social projects in the background.

The elderly, when faced with the insufficient implementation of public policies that meet their needs, struggles with difficulties in overcoming the negative consequences of social segregation due to the 
declining conditions of their health, physical capacity and limited income after retirement, compromising their well-being [6].

Bestetti [7] states that housing demand is a reality and it requires project solutions that offer more flexible designs to attend the elderly users in terms of their daily needs. According to Bestetti [7], most project guidelines are conducted with reference to the physically disabled resident and not the elderly. The exception relates to the Brazilian Technical Standard NBR 9050/2004 which incorporates some elements aimed at the elderly.

The challenge of the housing sector in Brazil is to insert this population in low-cost housing programs since a significant part of this population currently lives with an average monthly income of up to three minimum wages.

The concept of SH (social housing) is understood as a broader concept of "habitat" and it is to meet not only the function of safe shelter and conditions for the development of basic needs, but also the cultural and economic needs, understood by the Brazilian Government as an instrument of social inclusion and access to citizenship [8].

The need to provide housing for the elderly through housing programs of the federal government only gained strength with the enactment of Federal Law 12,418 of 2011, known as the Elderly Statute. Article 37 of this law points out that "The elderly have the right to decent housing within the natural family or surrogate, or unaccompanied by their families, when so desired, or even in public or private institution" [9].

Article 38 of the Elderly Statute states that in social or subsidized housing by public fund programs, the elderly enjoys priority in the acquisition of property for own house, observing a booking of at least 3\% of residential housing units that should preferably be situated on the ground floor, funding criteria consistent with pension and retirement of the elderly, elimination of architectural and urban barriers to their accessibility and implementation of urban equipment designed for the elderly [9].

In other countries, other solutions for housing the elderly are not associated with nursing homes. The United States, Canada and Europe have housing programs termed as residential senior which can afford partially or totally the population over 60 years old.

Bestetti [7] presents the various types of housing or accommodation available for this age group: assisted living, independent housing, congregated housing, continuing care retirement community, clinics and clinics specializing in Alzheimer Mal.

To understand the problems that older people may have in their everyday activities in housing, it is necessary to know the physical and psychological constraints related to this age group. According to Tilley cited from Bestetti [7], the physical changes that occur with advancing age of the elderly hinder their motor skills, factors are as follows:

- Eyesight tends to worsen, reaching less than half the 80 years;

- It is difficult to distinguish the colors violet, blue and green (due to yellowing of the lens);

- Joints becomes stiff;

- Most body size decreases;

- Weight can increase $2 \mathrm{~kg}$ every ten years;

- The strength of the hands is reduced $16 \% \sim 40 \%$ and the arms and legs is reduced $50 \%$;

- Lung capacity decreases by about $35 \%$, and the nose and ears increase in width and length.

Research has shown that the quality and design of the built environment affect in its use and frequency as well as in users' psychological, social and physical aspects. Therefore, the quality of architectural design should be determined by physical, psychological, social, cultural and economical characteristics of the elderly added to the physic-spatial factors, the environment, the urban regulations and the laws of the place. Quality must come from the purposeful stage (project) to the construction technique (execution).

Importantly, the quality of the built must be 
understood not only as a physical condition of the architectural object, or as a function of trial by an expert in this area, but also as a condition of satisfaction, cost-effectiveness and appropriateness of built space according to user expectations [10].

When built spaces do not meet the users' needs and expectations, the dissatisfaction created with the building may become a source of environmental stress and when experienced daily, the disturbance can cause frustration, irritation and tension and the following effects may occur: physiological (decreased immune resistance, abnormal heart rate and respiratory rate) or behavioral (decreased cooperation, increased hostility and aggressiveness, poor body posture and reduced facial contact) performance change (attention and memory deficits) [10].

Jones and Kinnan cited from Elali [10] indicate the following problems as the main stressors of the relationship with the physical environment: noise levels above the tolerance, high density, insufficient or excessive lighting, very low or very high temperature, difficulty with furniture (ergonometric/anthropometric problems) and little contact with the natural environment (considered important restorer of physical and mental balance).

On accident prevention, Jacob cited from Bestetti [7] points out that inside the house, the path and stairs should be properly illuminated, handrails should be placed at the point of imbalance and floor mats should be removed or fixed. Out on the street, as a pedestrian, the elderly should wear colorful clothes and stable shoes, observe the surface irregularities, the crossing points, put attention to road signs and vehicles.

Therefore, the construction standards should take into account the health and safety needs of older people. In houses, the obstacles that increase the risk of falls must be corrected or removed [11].

On the other hand, the quality of the built social housing for the elderly is not only limited to the building itself, but also covers the neighborhood and their community public facilities. According to Decree
No. 7,341 of October 22, 2010, the community public facilities are the facilities and spaces of urban infrastructure for public health services, education, welfare, culture, sports, leisure, public safety, supply, funeral services and the like.

Most daily activities of the elderly population are held in the vicinity of the residence and in the neighborhood through the walking mode, so the distance from the residence to trade, and community public facilities should allow its full spatial accessibility [12]. In addition, the offer of trade and community public facilities outside the residence should allow daily activity, autonomy and mobility of the elderly and may determine their satisfaction with the neighborhood and city life in general [12].

Still, with respect to housing, proper housing and good neighborhood are essential to the well-being of the elderly. For the elderly, proximity to family members, services, trade and transportation can mean the difference between positive social interaction and isolation.

According to Bestetti [7] a housing project for the elderly should take into consideration the following spatial aspects:

- access (visibility and distance);

- circulation (type and size);

- dimensions (rooms and equipment);

- architectural barriers (stairs, gaps, security system);

- environmental conditions (lighting, ventilation and heating, acoustics);

- finish (texture, temperature and padronage);

- maintenance conditions (easy to clean, adequacy and accessibility);

- psychodynamic aspects (color, line and size);

- technological aspects (communication system, fire safety and insolation control) and other aspects (visual warning bells, adequacy of facilities for computers and emergency lamp).

Given this reality, it is necessary that cities, including those with tourist character, provide 
qualified built spaces for the elderly. Therefore, it is up to the public administration of the cities to set up policies, programs and projects to the needs of the elderly. The City Hall of São Paulo through the Social Rental Program built the housing complex "Village of the Elderly", aimed at housing people over 65 years and with a monthly income of up to three minimum wages. In this context, this paper aims to analyze the spatial quality of the built environment of Village of the Elderly. The manuscript should be in MS Word format, submitted as an email attachment to our email address.

\section{Housing Policy in Central Areas}

Over the past decades, the central regions of Brazilian cities have undergone processes of real estate depreciation and spatial degradation, with consequent reduction of the resident population. This emptying of the central area can be justified by the following reasons:

- population displacement to other areas of the city;

- changes of uses and functions;

- displacement of public institution buildings;

- environmental degradation caused by pollution;

- public investment in urban infrastructure elsewhere in the city;

- funding for the production and marketing of real estate in other areas of the city, among other reasons $[13,14]$.

Facing the evacuation and loss of residents of the metropolitan downtown areas, the lever for the recovery of these areas are the housing programs. According to Maricato [15], the rehabilitation falls to governments and agents taking as a first step the recovery of buildings and public spaces through the recycling of existing buildings or the construction of new ones when the old ones do not justify any intervention.

In order to reverse the problem of space degradation, loss of residents, among others, the government has implemented urban policies of revalorization and renewal of these central areas. In the case of the City Hall of the Municipality of São Paulo City, we highlight the program "Living in the Center", which is a set of integrated municipal interventions coordinated by Housing Secretariat (in Portuguese: SEHAB (Secretaria de Habitação)), which aims at improving the living conditions of the centre's residents, enabling adequate housing for people who live or work downtown, avoiding the process of expulsion of the poorest population which often occurs in the political rehabilitation of urban centers [16].

This program had four areas: social rental housing, rental grant, integrated habitat rehabilitation perimeters (in Portuguese: PRIH (Perímetro de Reabilitação Integrada do Habitat)) and rental program [14]. According to Shimbo [14], this program resulted in the construction of 1,120 units by Residential Rental Program (in Portuguese: PAR (Programa de Arrendamento Residencial)) and social rental housing, 1,387 grants from the Rental Grant Program, and the beginning of the rehabilitation projects of integrated habitat rehabilitation perimeters-Luz and Glicério.

\section{Social Rental Program and Its Implementation in the Housing Set "Village of the Elderly"}

The Social Rental Program began from the State Law 10,365 of September 2, 1999 and the CFMH (Municipal Housing Fund Council) Resolution No. 23 dated June 12, 2002 of the Municipality of São Paulo.

Under this act, the objective of the program is to meet the housing demand for sectors of the population who do not have conditions to participate of other programs involving the purchase or rent. The units built through this program, with funds from the Municipal Housing Fund, are owned by the government.

The beneficiaries of the Social Rental Program are 
the single persons and families whose income does not exceed three minimum wages and belong primarily to the following groups: seniors over 60 years old, the homeless, people with special rights and residents in risky or unhealthy areas.

In Social Rental Program, the rent value of the apartment paid by residents is assigned according to the family composition and family monthly income, ranging from $10 \%$ to $15 \%$. The amounts paid by the beneficiaries of social rentals are returned to the Municipal Housing Fund.

The municipal authorities of the City of São Paulo, during managements from 2001 to 2004 and also from 2005 to 2008, implemented the Social Rental Program in the construction of the housing complex "Armando Amadeu", better known as "Village of the Elderly".

The building is located at 840 Carlos de Campos Avenue, in Pari neighborhood. The architectural design of "Village of the Elderly" is pioneer in Sao Paulo and it satisfied the demands of the GARMIC (Coordination Group for the Housing Achievement for Senior Citizens of the Capital), which works in partnership with the Municipal Council of the Elderly.
The architectural design of the building was developed by the Office VIGLIECCA \& ASSOC. and was inaugurated in 2007. The four-story building features the following architectural program: 145 apartments, 88 kitchenettes $\left(30 \mathrm{~m}^{2}\right)$ and 57 one-bedroom apartments $\left(42 \mathrm{~m}^{2}\right)$, three ballrooms, three elevators, library, community garden, boules pitch (unfinished), large green area and a water mirror in the center of the lawn. On each floor, there is a lounge with room to watch TV or play cards (Figs. 1 and 2).

\section{Materials and Methods}

Studies developed by Ornstein [17], Bestetti [7], Alucci [18] and Salcedo [19] were used as reference to evaluate the environmental quality of the built spaces of "Village of the Elderly".

This analysis allowed evaluating this complex through multimethod: relationship between the building and the public facilities of the community; accessibility to buildings and unbuilt spaces (by assessing the internal and external environments of the building, as well as points of access and circulation); safety and quality of housing.

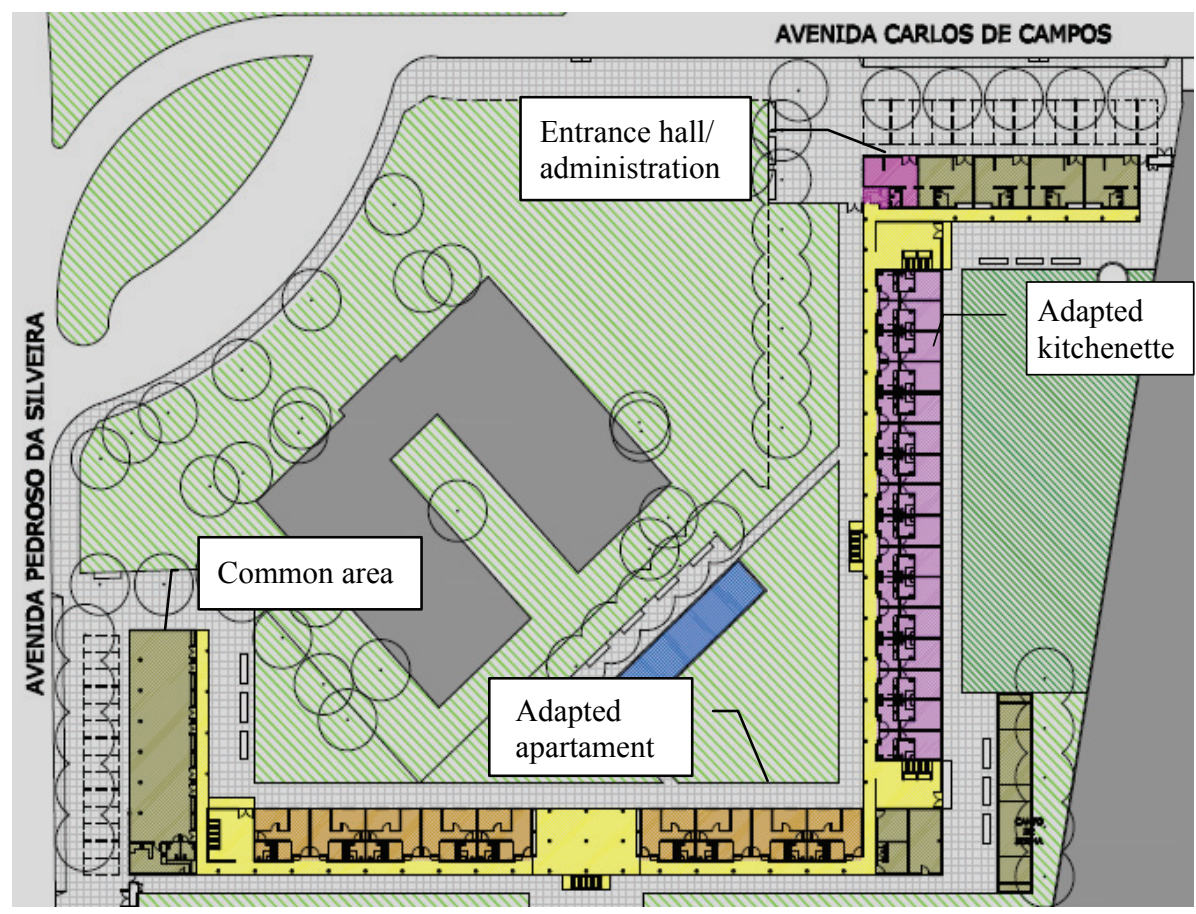

Fig. 1 Implantation of Village of the Elderly. 


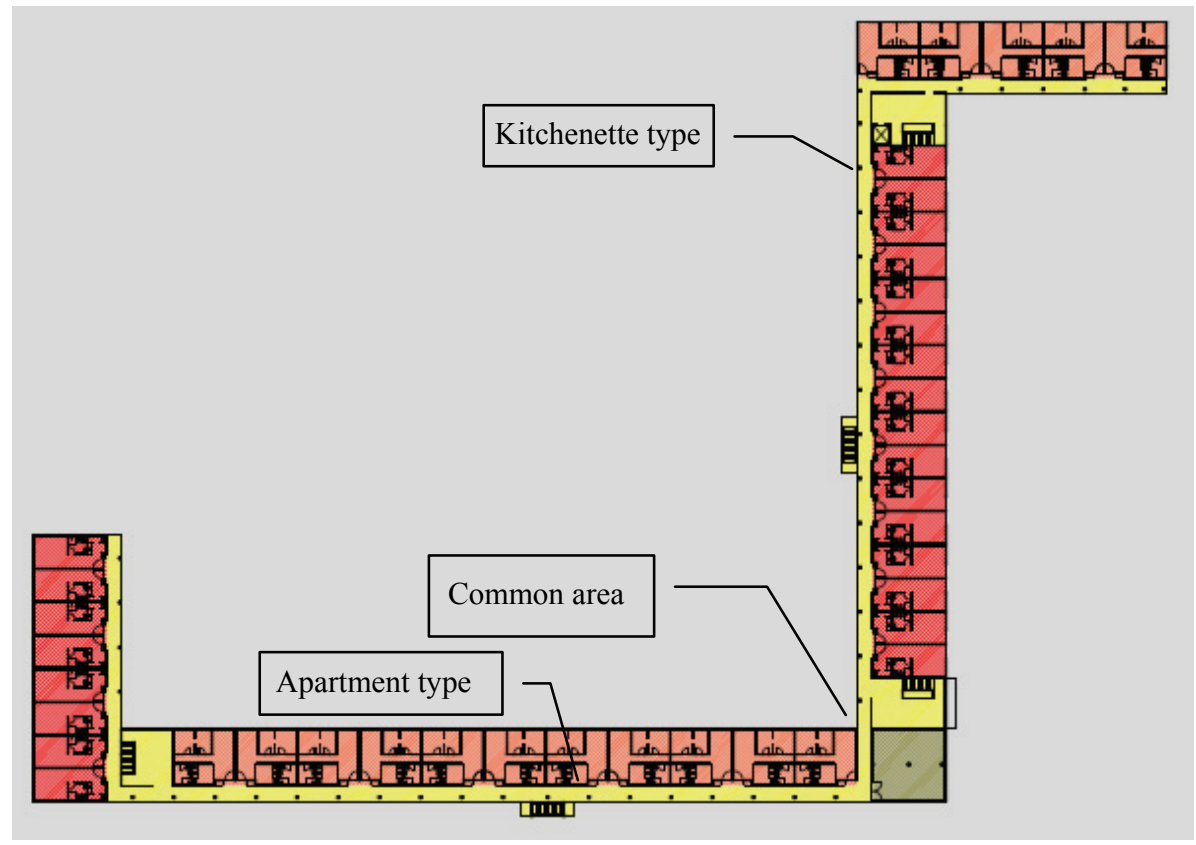

Fig. 2 Village of the Elderly: plant-type.

The analysis of the relationship of the building "Village of the Elderly" with the existing public facilities in the neighborhood was carried out from the location of the building and the accessibility to public transportation means and equipment for trade, health, leisure and culture.

The analysis of spatial accessibility in "Village of the Elderly" was evaluated by on-site observations, photographs and by defining a list of indicators using as reference the Brazilian Technical Standard NBR 9050 [20]. The indicators enabled the evaluation of internal and external spaces of the building. They were evaluated by a checklist where the evaluation criteria consisted of checking whether the rated space was appropriate or not according to the accessibility standard.

The analyses of accessibility and security are presented as important factors to evaluate the spaces for the elderly, since they must consider the spatial needs associated with aging, taking into account the degree of dependence of the elderly user. The aspects to be incorporated in these residences are: inclusion of support bar in bathrooms, slip-resistant flooring, adequate lighting, placement of handrails, presence of ramps substituting stairs, reversed locks, elimination of corners and wide doors. These elements can facilitate the life of the elderly.

For the analysis of spatial accessibility of the internal environment of the apartment type and kitchenette, elderly with reduced mobility-wheelchair users were taken into consideration. For this analysis, it was used as reference the study by Pereira [21] and the Brazilian Technical Standard NBR 9050 [20]. The first step was the analysis of the linear displacement range and the minimum area for a $360^{\circ}$ rotation or a wheelchair maneuver. A width of $0.90 \mathrm{~m}$ was adopted for the linear range, and a diameter of $1.50 \mathrm{~m}$ for the wheelchair rotation or maneuvering $\left(360^{\circ}\right)$.

The housing quality of "Village of the Elderly" was analyzed according to the following parameters: constructed area per unit, type and size of rooms, number of people per bedroom, insulation, ventilation and lighting.

The analysis of the area of the rooms was carried out according to the ergonomics for the elderly. The data that formed the basis for the proposals are the result of the intersection and analysis of various anthropometric tables in the book Human Dimension \& Interior Space [22], which presents two basic types of 
dimensions, static and functional or dynamic. Table 1 shows the scale values for the ideal area for rooms.

For the analysis of the quality of the bedroom, the evaluation was made according to the number of persons per bedroom, thus, the established value range is:

- excellent-one resident or a couple/sleeping room;

- good-two residents/sleeping room;

- regular-three residents/sleeping room;

- bad-four residents/bedroom;

- awful-more than four [19].

The ideal orientation for each type of room has been established according to the thermal stress and latitude of São Paulo [18], the actual orientation of each room window was taken from the floor plan of the apartment of the housing project. The scale of values is excellent when the window has the ideal orientation.

For multiple uses and bedrooms, they face north, northeast, east and southeast; for kitchens, they face east, southeast, south and southwest; and for laundries, they face east, north and west. It is bad when the orientation of the window does not meet the ideal orientation and awful when the environment has no window or the window is facing a corridor. The lighting, a factor that also depends on the size and placement of the openings, will be evaluated from the data in Table 2 .

As the office responsible for the project provided only the floor plans, the actual area of the windows was obtained from the Resident's Guide from one of the users during one of the visits to the building.

\subsection{Application of Questionnaires to Residents}

The questionnaires were given to residents during the second half of 2011. From a universe of 145 beneficiaries, 67 were interviewed. Taking as reference the simple random sample table for $95.5 \%$ confidence level [16] with a population raging from $151 \sim 200$ and with an error margin of $10 \%$ to more or less, the required minimum sample size would be 67 people. The questionnaire consisted of three parts, the first on the socioeconomic characteristics of residents, the second on the housing characteristics and the third comprised open questions related to the perception of users about their housing [23].

\section{Results and Discussion}

The analysis of the results is presented in the following order: socioeconomic characteristics of residents, community public facilities in the neighborhood, accessibility and security to buildings

Table 1 Scale for the ideal area of the rooms.

\begin{tabular}{llllll}
\hline \multirow{2}{*}{ Type of rooms } & \multirow{2}{*}{ Ideal area $\left(\mathrm{m}^{2}\right)$} & \multicolumn{4}{c}{ Scale } \\
\cline { 3 - 6 } & & $>25 \%$ (excellent) & $\geq 25 \%$ (good) & $\leq 25 \%$ (bad) & $<50 \%$ (awful) \\
\hline Eating room, kitchen laundry & 18.65 & $\geq 23.31$ & $18.65 \sim 23.30$ & $13.99 \sim 18.64$ & $\leq 13.98$ \\
Living room & 14.50 & $\geq 18.13$ & $14.50 \sim 18.12$ & $10.88 \sim 14.49$ & $\leq 10.87$ \\
Living room/single bedroom & 12.09 & $\geq 15.11$ & $12.09 \sim 15.10$ & $9.07 \sim 12.08$ & $\leq 9.06$ \\
Double bedroom & 15.17 & $\geq 8.03$ & $15.17 \sim 18.95$ & $11.38 \sim 15.16$ & $\leq 11.37$ \\
Adapted bathroom & 6.42 & $\geq 46.45$ & $6.42 \sim 8.02$ & $4.81 \sim 6.41$ & $\leq 4.80$ \\
kitchenette & 37.16 & $\geq 68.43$ & $37.16 \sim 46.44$ & $27.87 \sim 37.15$ & $\leq 27.86$ \\
One bedroom apartment & 54.74 & $54.74 \sim 68.42$ & $41.05 \sim 54.73$ & $\leq 41.04$ \\
\hline
\end{tabular}

Table 2 Scale of natural lighting.

\begin{tabular}{lllll}
\hline \multirow{2}{*}{ Type of room } & \multicolumn{3}{c}{ Scale } \\
\cline { 2 - 5 } & Excellent (\%) & Good (\%) & Bad (\%) & Awful (\%) \\
\hline Multiple use & $\geq 18.8$ & $15.0 \sim 18.7$ & $11.3 \sim 14.9$ & $\leq 11.2$ \\
Kitchen & $\geq 12.5$ & $10.0 \sim 12.4$ & $7.60 \sim 9.90$ & $\leq 7.50$ \\
Laundry & $\geq 12.5$ & $10.0 \sim 12.4$ & $7.60 \sim 9.90$ & $\leq 7.50$ \\
Bathroom & - & - & - & - \\
\hline
\end{tabular}


and unbuilt spaces and housing quality.

\subsection{Socioeconomic Characteristics of Residents}

Residents of Village of the Elderly were characterized by age, gender, family income and previous condition of housing. The 67 respondents and their families make up a total of 90 people. Most are women (56.67\%) and a minority, men (43.33\%). The larger sample group consisted of women aged between 70 and 79 years old $(25.56 \%)$, followed by the group of men in this same age group (23.33\%).

Regarding the income of residents, $97.01 \%$ has up to 1 minimum wage, $1.49 \%$ up to 2 minimum wages and $1.49 \%$ up to 3 minimum wages. Therefore, residents have incomes up to 3 minimum wages and comply with the requirements for selection of Social Rental Program. With this question, it was also possible to verify that the residents were satisfied with the low rents, for being able to pay for their housing brings the elderly a sense of well-being and contentment.

\subsection{Environmental Quality of the Built Area of Village of Elderly}

The environmental quality of the built space of Village of the Elderly is analyzed by the following indicators: community public facilities in the neighborhood, accessibility to buildings and unbuilt spaces (by assessing the internal and external environments to the building, as well as the access points and circulation), housing safety and quality.

\subsection{Community Public Facilities in the Neighborhood}

The building "Village of the Elderly", built in Pari neighborhood, central area of São Paulo, is in an area with a consolidated infrastructure and with considerable supply of commercial establishments, community public facilities for social, cultural and educational assistance as well as leisure and health assistance with easy access to public transportation (bus), allowing daily activity, autonomy and mobility of the elderly.

Nonetheless, the nearest subway station is the "Armenia", located about $2 \mathrm{~km}$ away, which hinders the access of the elderly. In the immediate surroundings, apart from commercial and service buildings, there are many residential houses. The Strategic Master Plan of São Paulo 2002, aiming to revalue the District Pari implemented social housing, improved the quality of community facilities and transport [24] (Fig. 3).

\subsection{Accessibility and Security to Buildings and Unbuilt Spaces}

The first assessment in "Village of the Elderly" was conducted through an interview with the architect responsible for the project. It was asked: "How the criteria for accessibility of disabled people, security in the building, emergency routes in case of fire, sustainability (solar collection, recycling and storage of rainwater) influenced the architectural design?" According to Héctor Vigliecca, all “these criteria are already a constraint of the architectural party" $[25,26]$.

Still regarding the spatial accessibility, the residents were asked to rate the degree of accessibility of the building, through a scale ranging from "poor, fair, good or excellent". For $34.33 \%$ of residents, the building has excellent accessibility, while 55.22\% considered it "good". Only $10.45 \%$ of residents considered it "regular". Most residents of Village of the Elderly mentioned the presence of elevators as a positive element in relation to accessibility. For them, the presence of three-column lifts at strategic points of the building (its "vertices") is suitable, requiring little horizontal displacement for access. It is reported that their maintenance is constant, even when there is a problem; The distance between the elevators is not very big. In addition, for those who have more physical disposition, the presence of stairs facilitates the path to all floors of the building.

The analysis of spaces for housing the elderly was 


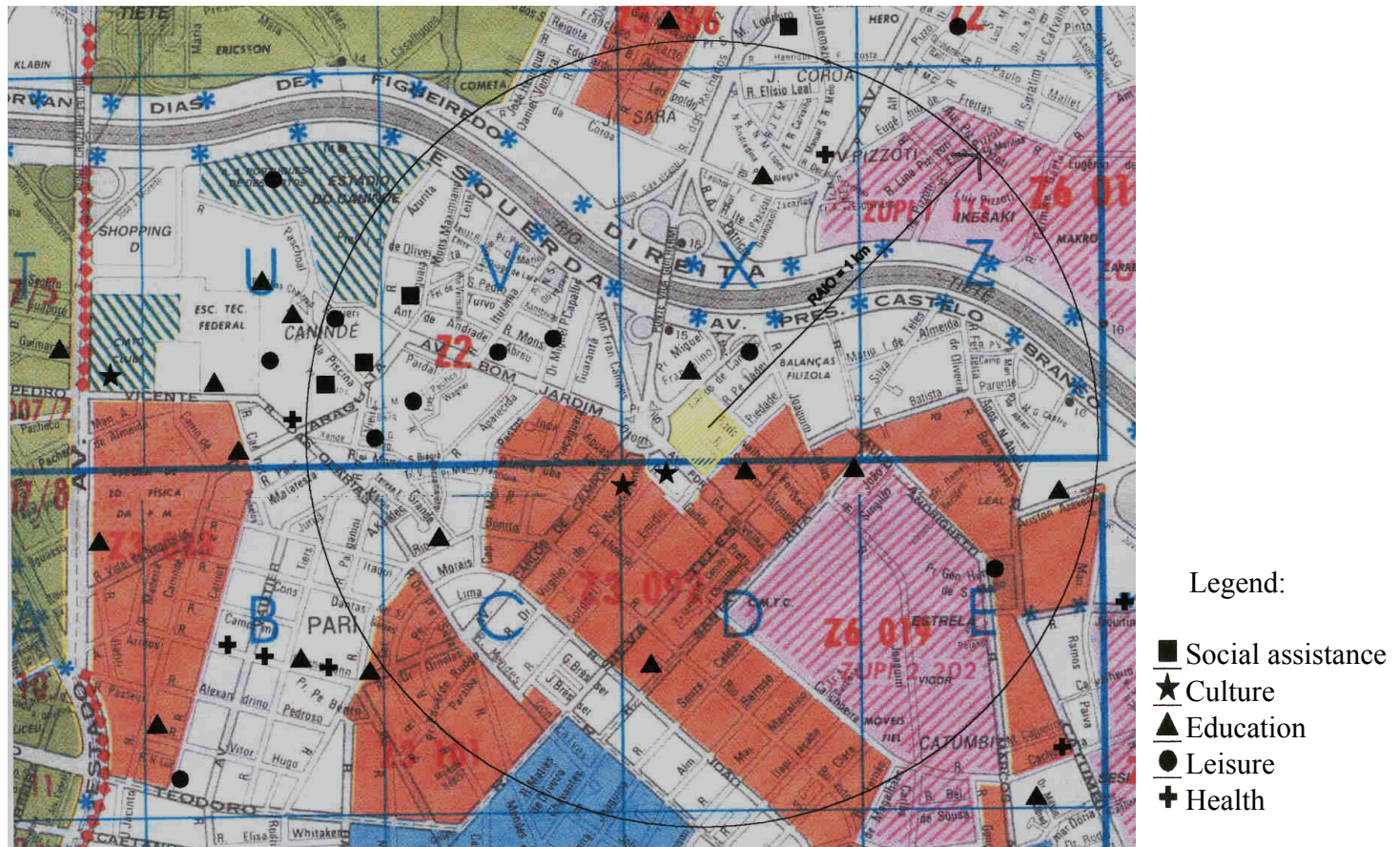

Fig. 3 Location of the community public facilities surrounding "Village of the Elderly".

Source: Technical Development Center of the Municipality of São Paulo City (in Portuguese: CEDTEC-PMSP (Centro de Desenvolvimento Técnico-Prefeitura Municipal de São Paulo), 2012).

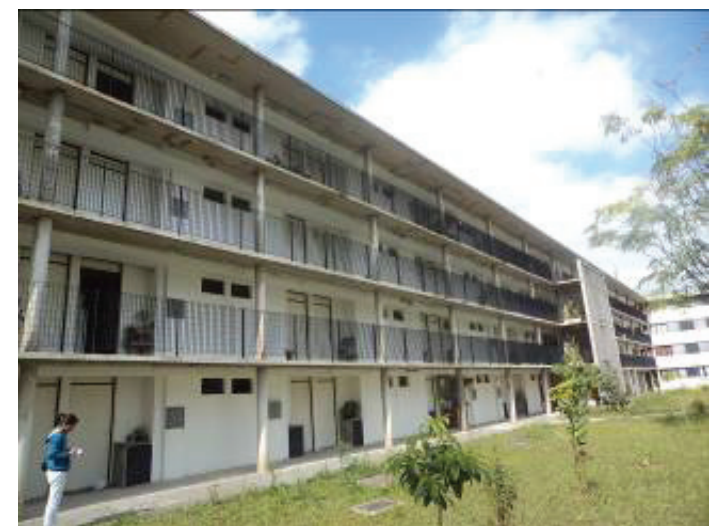

(a)

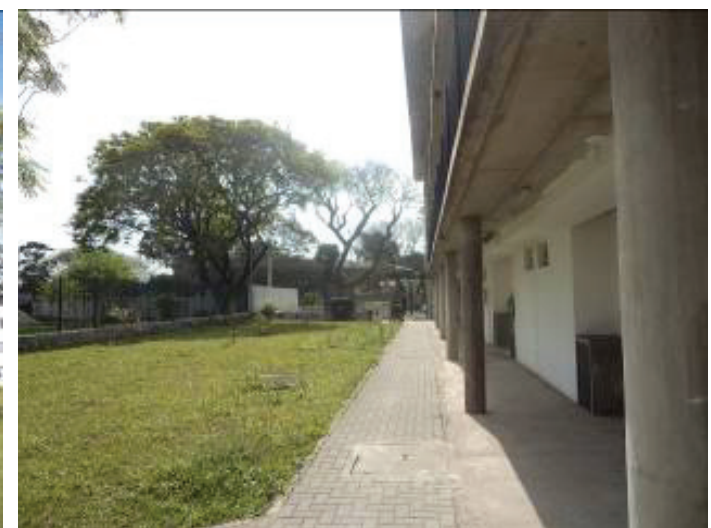

(b)

Fig. 4 Access to the building: (a) overview of the horizontal circulation of the building; (b) ground floor circulation area.

based on the following criteria: internal circulation of the building (horizontal and vertical), and analysis of the housing unit (apartment type).

The first analysis refers to the access to the building. These areas were examined under the optical displacement of physically disabled people, the wheelchair user and the visually impaired. In this analysis, the following problems were identified:

(1) Access to the building: The access to the apartments does not show unevenness that could jeopardize the entry of any elderly to the building (Figs. 4a and 4b);

(2) Vertical circulation: Access to floors can be accomplished either by stairs (which have body guards in accordance with accessibility standards) or by elevators (Fig. 5);

(3) Horizontal circulation: The areas of horizontal circulation (corridors) are wide. They have dimensions compatible for wheelchair traffic aided by an escort (Fig. 6a); 


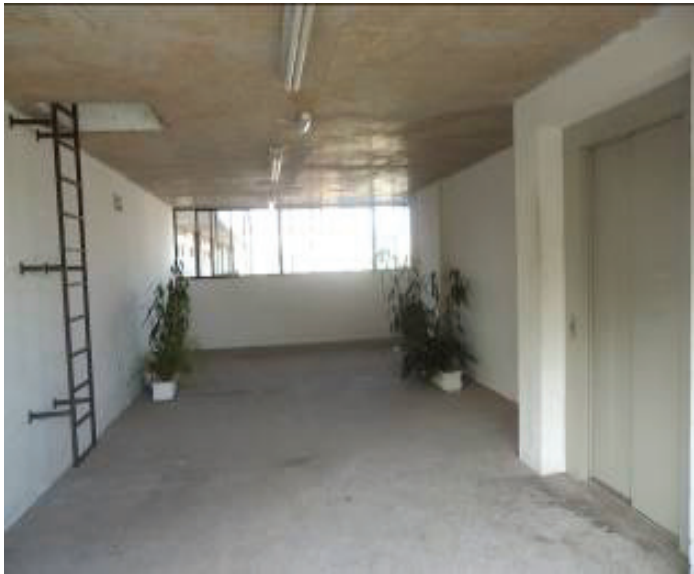

Fig. 5 Access to the elevator.

(4) Gateway of apartments: Access to the interior of the apartments have doors with dimensions suitable for the disabled. Wheelchair users and the inner doors of the apartments are also in accordance with the Brazilian Technical Standard NBR 9050 (Figs. 6b and 6c).

The analysis of the types of apartments detected that the project included the construction of only nine apartments (one bedroom) and 16 kitchenettes (on the ground floor) with adaptation to people with limited mobility.

In these units, the internal space was designed for wheelchair movement. The bathroom was designed in accordance with the references presented in the Brazilian Technical Standard NBR 9050, that is, it had side support bars near the areas of the shower and the toilet (Figs. 7a and 7b).

Due to the profile of users, the second phase of this research examined the remaining housing unitsapartments and kitchenettes, defined as Types I and II (Figs. 8a and 7b).

Analysis showed that the plants of the apartments Types I and II do not consider that aging brings some mobility restrictions (temporary or permanent). In the layout proposal by the authors of the project, it is visible the lack of space or useful area for maneuvering a wheelchair (Figs. 8a and 8b).

One of the most challenging environments is the bathroom (Figs. 8a and 8b). In units Types I and II, there is no area for wheelchair displacement. The NBR 9050 says that the minimum diameter for a $360^{\circ}$ maneuvering of a wheelchair with no displacement is $1.50 \mathrm{~m}$. There is no room area for transference to the toilet and/or to the shower area. The dashed lines shown in Figs. 8a and 8b show the wheelchair rotation of $360^{\circ}$ without displacement. The lack of foresight on the proposed layout future adaptation in the project stage makes any future changes nonviable when any adaptation is needed.

Table 3 shows the comparative analysis of environments on the maneuver or rotation area for the wheelchair.

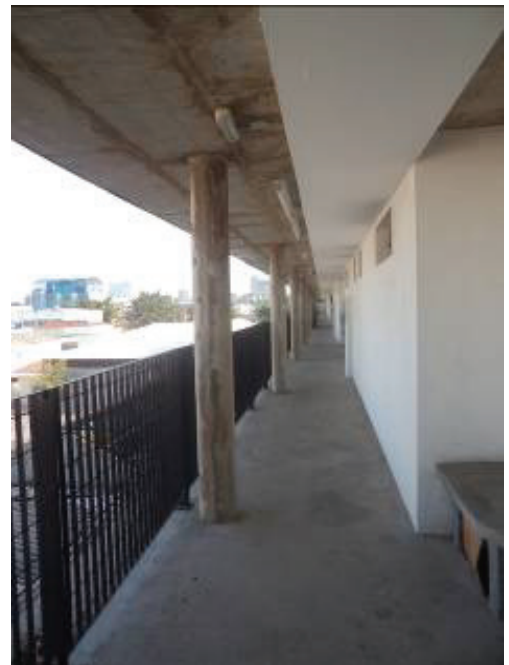

(a)

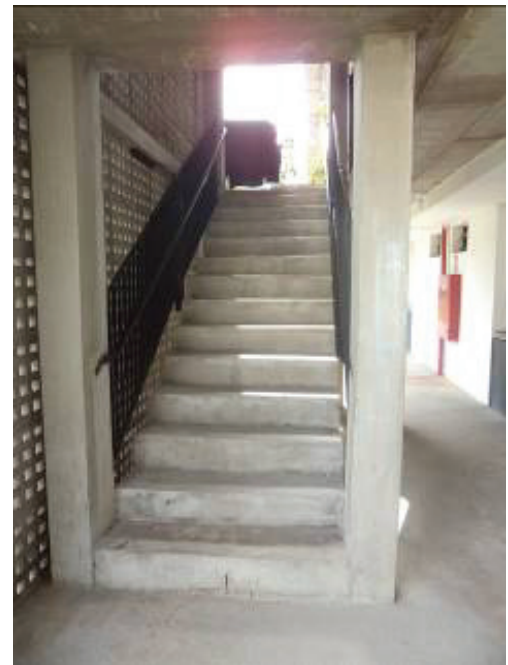

(b)

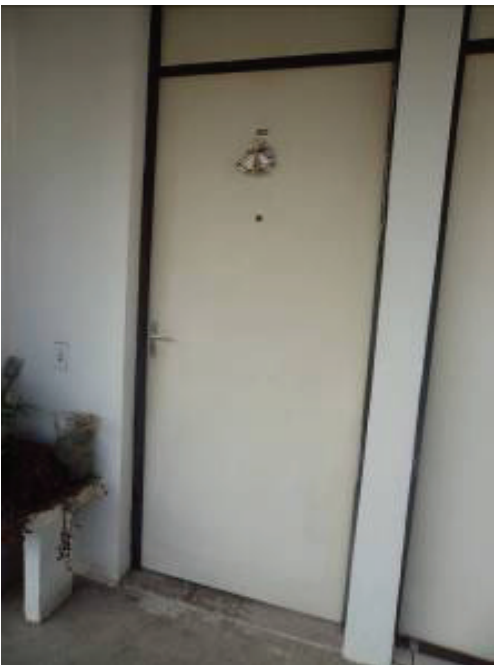

(c)

Fig. 6 Access to the apartment: (a) circulation area; (b) stairs; (c) gateway of the apartment. 


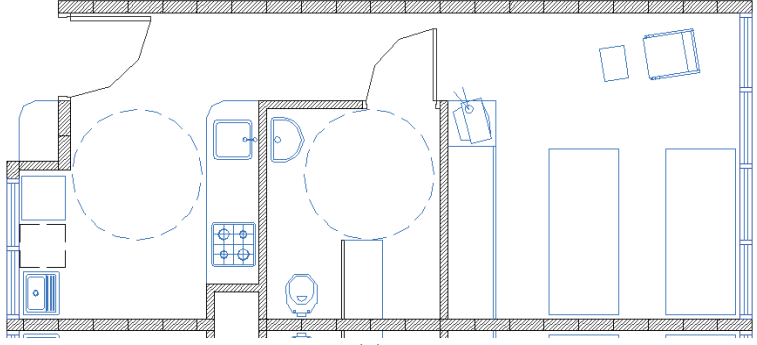

(a)

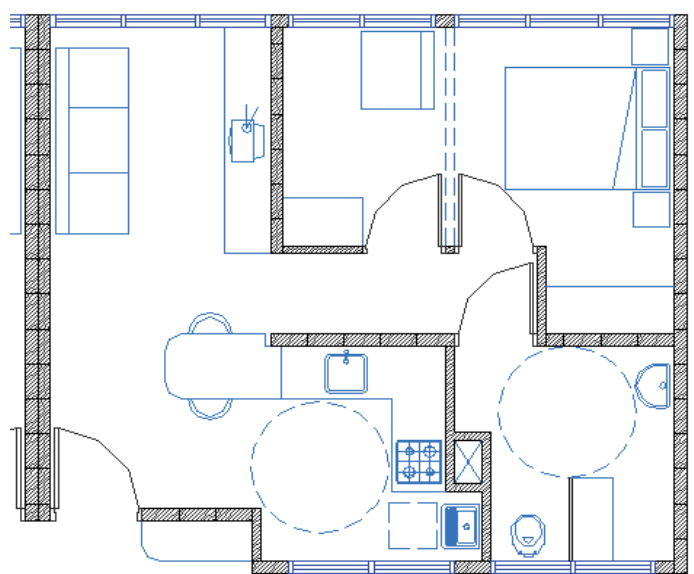

(b)

Fig. 7 Project of accessible units in the apartments of Village of the Elderly: (a) Type I; (b) Type II.

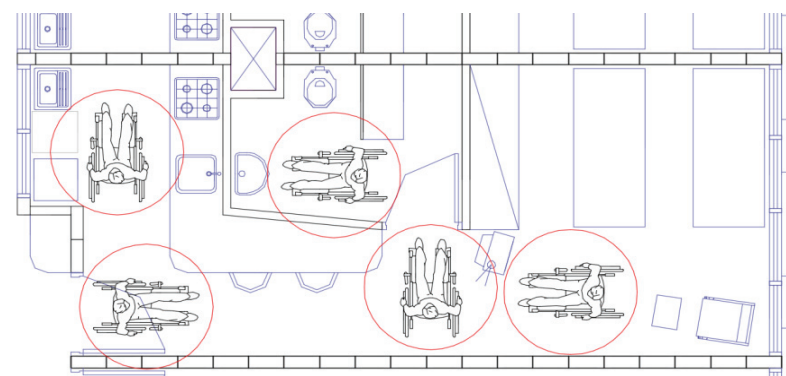

(a)

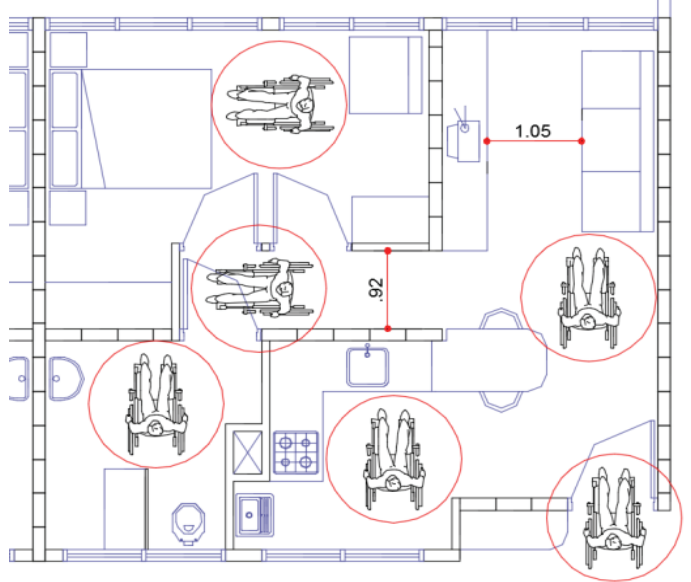

(b)

Fig. 8 Floor plan of apartments of Village of the Elderly: (a) Type I; (b) Type II.
Table 3 Summary of evaluations of the maneuver or rotation area of wheelchair user.

\begin{tabular}{lll}
\hline Environments & Apartment Type I & Apartment Type II \\
\hline Entrance-main door & Adequate & Adequate \\
Living-room & - & Adequate \\
Kitchen & Inadequate & Inadequate \\
Hall/circulation & Inadequate & Inadequate \\
Bathroom & Inadequate & Inadequate \\
Bedroom 1-master & - & Adequate \\
Bedroom 2-single & Adequate & - \\
\hline
\end{tabular}

In the apartment Type I, analysis can be seen that the kitchen and bathroom are inadequate to this user (resident), depending on the square footage of the environments and the furniture arrangement because there is no space for a wheelchair user to move freely in apartment. Regarding the environments in apartment Type I, $60 \%$ of them are considered adequate and in apartment Type II, 50\%.

Regarding the external spaces, Village of the Elderly is designed to meet the needs of interaction among residents, through a community experience. Accesses to the common living areas are performed in level, as shown in Figs. 9 and 10.

As over the years the elderly begin to gradually lose sight, reflection and mobility, it is necessary that all units provide spatial accessibility and security. However, only $17.2 \%$ of the apartments and kitchenettes of this condominium is inclusive, the other units do not provide full accessibility and security (Table 4).

As regards the analysis of accessibility, this paper deals only with the evaluation of the space issue, however, for further consideration, other issues such as lighting and furniture of the apartments need to be analyzed.

\subsection{Housing Quality}

The quality of housing of Village of the Elderly was analyzed according to the following indicators:

- built area per unit;

- built area per room;

- built area per inhabitant; 


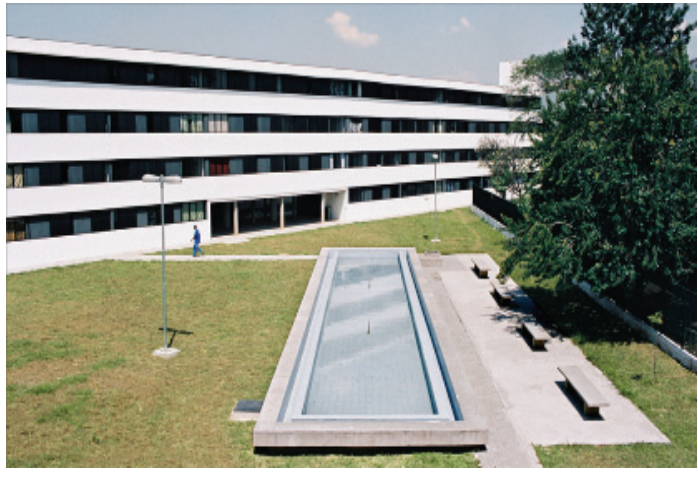

Fig. 9 Common area.

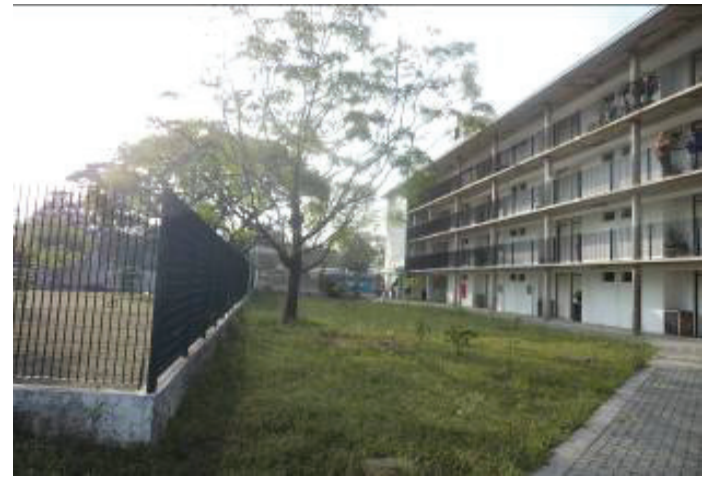

Fig. 10 Main entrance.

Table 4 Synthesis of the accessibility diagnosis.

\begin{tabular}{|c|c|c|c|c|}
\hline \multirow{2}{*}{ Environment } & & & \multicolumn{2}{|c|}{ Adaptation to the accessibility standard (NBR 9050) } \\
\hline & & & Yes & No \\
\hline Access to the building & & & $\sqrt{ }$ & \\
\hline \multirow{3}{*}{$\begin{array}{l}\text { Horizontal circulation } \\
\text { (corridors) }\end{array}$} & Width & & $\sqrt{ }$ & \\
\hline & Floor typ & & $\sqrt{ }$ & \\
\hline & Tactile flc & varning and directional) & & $\sqrt{ }$ \\
\hline \multirow{5}{*}{ Vertical circulation } & \multirow{3}{*}{ Stairs } & Type of floor & $\sqrt{ }$ & \multirow{3}{*}{$\sqrt{ }$} \\
\hline & & Warning and directional signs & & \\
\hline & & Handrail & $\sqrt{ }$ & \\
\hline & \multirow{2}{*}{ Elevator } & Gap between floors & $\sqrt{ }$ & \multirow[b]{2}{*}{$\sqrt{ }$} \\
\hline & & Warning signs & & \\
\hline \multirow{3}{*}{$\begin{array}{l}\text { Apartment } \\
\text { Types I and II }\end{array}$} & Kitchen & & & $\sqrt{ }$ \\
\hline & Bathroom & & & $\sqrt{ }$ \\
\hline & Bedroom & & & $\sqrt{ }$ \\
\hline \multicolumn{3}{|c|}{ Communication and visual signaling } & & $\sqrt{ }$ \\
\hline
\end{tabular}

- number of people per bedroom;

- environmental comfort;

- level of satisfaction with current housing.

The quality of built area per housing unity is shown as follows: The real area of $30 \mathrm{~m}^{2}$ kitchenette is bad compared to the ideal area of $37.16 \mathrm{~m}^{2}$ (living room-bedroom: $12.09 \mathrm{~m}^{2}$, pantry-kitchen-laundry: $18.65 \mathrm{~m}^{2}$ and adapted bathroom: $6.42 \mathrm{~m}^{2}$ ), and the area of the one bedroom apartment of $42 \mathrm{~m}^{2}$ is also bad compared to the ideal area of $54.74 \mathrm{~m}^{2}$ (double bedroom: $15.17 \mathrm{~m}^{2}$, living room: $14.50 \mathrm{~m}^{2}$, pantry-kitchen-laundry: $18.65 \mathrm{~m}^{2}$ and adapted bathroom: $6.42 \mathrm{~m}^{2}$ ). Both the kitchenettes and the one-bedroom apartments have insufficient areas that make it difficult to carry out activities and restrict the mobility of the elderly.

The quality of built area per room is shown as follows: Of the 67 visited housing units, 226 rooms studied in the building showed that $21.24 \%$ have rooms with areas that were classified as "good", compared to the ideal areas, while $38.05 \%$ rated "bad" and 40.71\% "awful".

The quality of number of people per bedroom is shown as follows: The analysis of the number of people per bedroom and the area available for each resident in his apartment is an important factor to evaluate the comfort of the users. Of the 67 units visited, 97.01\% shows the number of people per bedroom classified as "excellent" (and of this 97.01\%, $71.64 \%$ of the dormitories were intended for a single person and $25.37 \%$ for a couple). It was classified as "regular" (91.49\%) the apartment that housed three people per bedroom (actually the living room was used as bedroom) and as "awful" (1.49\%) the one 
housing five people per bedroom (in this case the living room was also used as bedroom).

The quality of environmental comfort is shown as follows: Analysis of the item "insulation" in the rooms evaluated in the building showed that $51.33 \%$ of the windows of the rooms were properly oriented relative to the sun, being rated as "excellent". Other $30.09 \%$ were classified as "bad" for having openings with inadequate guidelines (west or south), and $18.58 \%$ of the rooms had insulation classified as awful for not having openings. In the bathrooms of kitchenettes, the ventilation is performed by pipelines.

The evaluation of the item "lighting" is an important aspect to assess the health of housing. $11.06 \%$ of the analyzed rooms were classified as "excellent", while $11.06 \%$ accounted for the option, "good"; 18.58\% option, "bad" and 59.30\% option, "awful". These data show that most of the area of the openings is insufficient to illuminate the environments as well, the lack of openings directed outwards in the bathrooms of kitchenettes also contributed to the increase of the unsatisfactory percentage.

The degree of satisfaction with housing is shown as follows: Regarding the users' perception of their homes, one of the items discussed was the degree of satisfaction of the users in relation to their current housing compared to their previous housing. So when they were asked: "Has your housing improved from your previous one?" Most respondents said that they were satisfied and many of them also mentioned their satisfaction to be able to pay a fair price for the space they inhabited.

Regarding the perception of the built space of their current residence, the majority of the respondents claimed to have pleasant sensations (64.18\%); Only to $19.40 \%$ of them, their homes brought negative images (lack of space, lack of some environments, desire to move away, enmities with the neighbors); $5.97 \%$ of them expressed that the word home brought them images from divided environments, and other 5.97\% did not answer this question.

\section{Conclusions}

The housing complex "Village of the Elderly" implemented by the municipal government of São Paulo City through the Social Rental Program has delivered some of the requirements of the elderly needs such as: accessibility, safety, proximity to public transportation (bus), commerce and community public facilities, rental value proportional to the monthly income of the beneficiary and group socialization activities. However, the housing units "kitchenettes and one-bedroom apartment" do not meet the needs of the elderly due to their insufficient areas for the performance of daily activities, for the accommodation of furniture and for restrictions to mobility, causing dissatisfaction, stress and accidents to users.

The recommendation to the governments of the cities is to create policies, programs and social housing projects for the elderly in consolidated neighborhoods with community public facilities, housing units with a minimum of one bedroom and collective spaces of preventive health and socialization. Projects must meet the physical, psychological, social, cultural and economic necessities of the users, they should consider access, circulation, suitable coatings, maintenance conditions, size of the rooms that allow the accommodation of furniture, use and circulation with wheelchairs, heating and ventilation as well as psychodynamic and safety aspects.

\section{Acknowledgments}

The authors thank FAPESP (Process No. 2010/16424-6) for the aid granted to the research, the residents of Village of the Elderly, the Municipality of São Paulo and the office VIGLIECCA \& ASSOC.

\section{References}

[1] UN (United Nations). 2013. "Population Policy." UN. Accessed July 23, 2013. http://www.un.org/en/development/desa/population/them e/policy/index.shtml. 
[2] Pan American Health Organization. 2009. Interagency Network of Information for Health. Report of status and trends: demographics and health.

[3] Brazilian Institute of Geography and Statistics. 2014. “2010-2013 Census-Elderly Population.” Brazilian Institute of Geography and Statistics. Accessed August 18, 2014. http://www.censo2010.ibge.gov.br/sinopse/inde x.php?uf $=35 \&$ dados $=26 /$.

[4] Monteiro, L. C. A. 2012. "Public Housing Policies for the Elderly: A Study on the Exclusive Condominiums." Ph.D. thesis, Federal University of São Carlos.

[5] Moreira, M. de M. 2006. "O Envelhecimento da População Brasileira em Nível Regional; 1940-2050." Associação Brasileira de Estudos Populacionais. Accessed September 15, 2014. http://www.abep.nepo.unicamp.br/docs/anais/PDF/1998/a 252.pdf. (in Portuguese)

[6] Liu, Y., Dijst, M., and Geertman, S. 2015. "Residential Segregation and Well-Being Inequality over Time: A Study on the Local and Migrant Elderly People in Shanghai." Journal Cities 49: 1-13.

[7] Bestetti, M. L. T. 2006. "Housing for Seniors: The Work of the Architect, Architecture and City". Ph.D. thesis, University of São Paulo.

[8] Medvedovski, N. S. 2009. "Management of Collective Spaces in Social Housing - The Denial of Basic Needs of Users and the Quality of Daily Life and Habitat." In Proceedings of 2009 National Meeting of the Project Quality and Brazilian Symposium on Built Environment, 111-21.

[9] Brazil Special Secretariat for Human Rights. 2004. Federal Law No. 10.741: Statute of the Elderly.

[10] Elali, G. A. 2010. "Projectual Process and Environmental Stress: Exploring Aspects That May Influence the User-Environment Relationship." In Quality in Building Projects, organized by Fabrício, M. M., and Ornstein, S. W. San Carlos: RiMa Publisher.

[11] World Health Organization. 2005. Active Aging: A Health Policy. Translated by Gontijo, S. Brasilia: Pan American Health Organization.

[12] Temelová, J., and Dvoraková, N. 2012. "Residential Satisfaction of Elderly in the City Centre: The Case of Revitalizing Neighborhoods in Prague.” Journal Cities 29: 310-7.

[13] Silva, L. O. 2005. "Rehabilitation of Downtown Sao Paulo." In Proceedings of 11th National Meeting of the National Association of Post-Graduate Studies and Research in Urban and Regional Planning, 1-12.

[14] Shimbo, L. Z. 2011. "Urban Design and Housing in the Downtown Area of Sao Paulo." In Proceedings of
National Meeting of the National Association of Post-graduate Studies and Research in Urban and Regional Planning, 1-15.

[15] Maricato, E. 2001. Brazil, Cities: Alternatives to the Urban Crisis. Petrópolis, RJ: Vozes.

[16] Municipality of São Paulo. 2004. Living Downtown Program. São Paulo: Municipality of São Paulo.

[17] Ornstein, S. W. 1992. POE (Post-occupancy Evaluation) of the Built Environment. São Paulo: Publisher of the University of São Paulo.

[18] Allucci, M. P. 1998. "Criteria Relating to the Ventilation Requirements in the House." In Institute of Technological Research, Implementation of Housing Complexes: Recommendations for Climate Adaptation and Acoustics. São Paulo: Pini.

[19] Salcedo, R. F. B. 2007. Rehabilitation of Residence in the Historic Centers of Latin America: Cusco (Peru) and Ouro Preto (Brazil). São Paulo: Editora UNESP (Univ Estadual Paulista).

[20] Brazilian Association of Technical Standards. 2004. NBR 9050: Accessibility to Buildings, Furniture, Spaces, and Urban Equipment.

[21] Pereira, G. M. 2007. “Acessibilidade Espacial na Habitação Popular: Um Instrumento para Avaliação de Projetos (Spatial Accessibility on Housing: An Instrument for Evaluation of Projects)." Master's dissertation, Federal University of Santa Catarina. (in Portuguese)

[22] Panero, J., and Zelnik, M. 2002. Human Dimensioning for Interior Spaces: A Book for Consultation and Reference for Projects. Barcelona: Editorial Gustavo Gili.

[23] Pereira, T. C., and Salcedo, R. F. B. 2012. "Ambience of the Historic Center of São Paulo.” Rental Social Program and Its Repercussions on the Architectural Design of the Village of the Elderly. FAPESP (Fundação de Amparo à Pesquisa do Estado de São Paulo).

[24] Municipality Of São Paulo. 2002. CFMH (Municipal Housing Fund Council) Resolution No. 23: Rental Social Program.

[25] VIGLIECCA \& ASSOC. 2012. "Descriptive Memorial, Pictures Referring to Plans, Sections and Elevations of the Housing Complex Village of the Elderly and Photographs." VIGLIECCA \& ASSOC. Accessed January 13, 2012. http://www.vigliecca.com.br/pt-BR/pro jects/elderly-housing\#memorial.

[26] VIGLIECCA \& ASSOC. 2011. "Village of the Elderly." VIGLIECCA \& ASSOC. Accessed June 10, 2011. http://www.vigliecca.com.br/pt-BR/projects/elderly-housi $\mathrm{ng} /$. 